\title{
Organic acid and carbohydrate changes in carrot and wheat bran fortified set-type yoghurts at the end of refrigerated storage
}

\author{
Zehra Güler \\ Mustafa Kemal University, Agricultural of Faculty, Department of Food Engineering, Tayfur Sokmen Campus 31034 Antakya-Hatay- \\ TURKEY
}

Email address:

zguler@mku.edu.tr / zehra_guler@yahoo.com.tr(Z. Güler)

To cite this article:

Zehra Güler. Organic Acid and Carbonhydrate Changes in Carrot and Wheat Bran Fortified Set-Type Yoghurts at the End of Refrigerated Storage. Journal of Food and Nutrition Sciences. Vol. 1, No. 1, 2013, pp. 1-6. doi: 10.11648/j.jfns.20130101.11

\begin{abstract}
The effects of using of wheat bran (1\%), carrot (1\%) and wheat bran (1\%) +carrot ( $1 \%)$ as a supplement on $\mathrm{pH}$, organic acids, carbohydrates and viscosity of yoghurt as well as overall acceptability were investigated. Fortification of milk with wheat bran resulted in a significant $(\mathrm{P}<0.01)$ increase in oxalic, orotic, pyruvic, lactic, formic, acetic, propionic and hippuric acid contents, and a decrease in total sugar content of yoghurt. The lowest level of total organic acid and a slow post acidification rate were observed for yoghurt made with carrot which was much more prefered by panelists at the end of refrigerated storage. Fortification also led to an increase in viscosity of yoghurts. At the end of storage, there was a significant $(\mathrm{P}<0.05)$ increase in viscosity of control yoghurt, whereas fortified yoghurt did not any change. Increases in lactic acid (from 9084 to $10823 \mathrm{mgkg}^{-1}$ ) and formic acid (from 665 to $802 \mathrm{mgkg}^{-1}$ ) contents of control yoghurt resulted in a significant $(\mathrm{P}<0.05)$ decrease in overall acceptability score (from 7.5 to 6.2 ). It was concluded that yoghurt samples with wheat bran (1\%) and wheat bran $(1 \%)+$ carrot $(1 \%)$ had the highest total organic acid content (about $\left.14200 \mathrm{mgkg}^{-1}\right)$ and titratable acidity (about $1.85 \%$ as lactic acid) were received the lowest overall acceptability score ( 5.6 out of 9 ) by panelists.
\end{abstract}

Keywords: Yoghurts, Organic Acids, Sugars, Wheat Bran, Carrot

\section{Introduction}

Today, consumers have a wide variety of dairy foods to meet their taste, nutrition, health, and convenience needs. Culture-containing dairy foods such as yoghurt are an excellent source of many of milk nutrients and also they may offer health benefits [1] for hypercholesterolemia and certain gastrointestinal conditions [2].These beneficial effects are due to their mainly organic acid contents since organic acids tend to exert preservative effect by controlling the growth of contaminating spoilage and pathogenic organisms [3]. Lactic acid fermentation also contributes to improved storage qualities, physical properties and flavour. Prebiotics are nondigestible food ingredients that beneficially affect the host by selectively stimulating the growth an/or activity of one or a limited number of bacterial species already resident in the colon, and thus attempt to improve host health [4] .

Consumers have been recently concerned about fiberrich foods due to their healthy reasons. By products like wheat bran are "nondigestible" which is called as prebiotics. Wheat bran has dietary fiber $(43.2 \%)$, cellulose $(8.7 \%)$, hemicellulose $(28.3 \%)$, lignin $(3.2 \%)$, pectin $(3.0 \%)$ moisture $(10.3 \%)$ and nitrogene $(2.64 \%)$. Wheat bran and its fractions have recently been reported to be strong anticarcinogens for colon carcinogenesis in rats [5]. Carrots are now increasingly consumed, mainly due to their pleasant flavour and perceived health benefits related to their vitamins, minerals and dietary fibre (about 31.99\% crude fiber) and well-known antioxidants such as terpenoid $\beta$-carotene [6]. The optimal dietary manipulation could be a good alternative in preventing, mainly carcinoma diseases. One of the ways of preventing diseases may be the together use of lactic cultures and naturel prebiotics. Studies on the addition of fruits or byproducts having high fiber content to milk prior to fermentation process are scarce. Only a few studies have been carried out on conventional fiber fortified yoghurt and flavoured milk drink $[7,8]$. In these studies, sweeted plan yoghurt or milk were produced. Therefore, the objective of this study was to 
determination the quality properties of yoghurts fortified with wheat bran $(1 \%)$, carrot $(1 \%)$ and carrot $(1 \%)+$ wheat bran $(1 \%)$. There will also be investigated the effects of using of wheat bran and carrot as a supplement on lactic acid fermentation. As quality attributes, we performed to acidity, organic acid, apparent viscosity and overall acceptability, which are important parameters in acceptability of products. So the use of by products of cereal industry in yoghurt product will be investigated.

\section{Materials and Method}

\subsection{Materials}

This study was carried out with cows' milk collected from Hatay province. YC-380 type commercial yoghurt culture containing Str. thermophilus and Lb. delbrueckii subsp. bulgaricus was used (Chr.Hansen-Peyma, Istanbul, Turkey). Wheat bran was used as nonpurified fiber source. Wheat was washed with top water and then was dryed. After milling process to make wheat flour, wheat bran as a byproduct was obtained for yoghurt-making. Carrot (Daucus carota L.) roots with orange color were washed and brushed under running water. Washed roots were manually peeled $(1 \mathrm{~mm})$, topped and tailed $(1.0-1.5 \mathrm{~cm})$ using a sharp knife, and grated.

\subsection{Yoghurt Production}

Milk heated to $85^{\circ} \mathrm{C}$ for $30 \mathrm{~min}$ using batch pasteurization and cooled to $45^{\circ} \mathrm{C}$ in a water bath. Yoghurt culture inoculated at a ratio of $20 \mathrm{~g} 100 \mathrm{~L}^{-1}$ milk for all the samples. Then milk was dispensed into Polystyrene plastic cups containing wheat bran $(1 \%)(\mathrm{w} / \mathrm{w})$, carrot $(1 \%) \mathrm{w} / \mathrm{w})$ and wheat bran $(1 \%)(\mathrm{w} / \mathrm{w})+\operatorname{carrot}(1 \%)(\mathrm{w} / \mathrm{w})$, and incubated at $43^{\circ} \mathrm{C}$. No fortified milk was control yoghurt. When yoghurt $\mathrm{pH}$ reached to 4.65 , samples were removed from incubator, and transferred to a cold room at $4^{\circ} \mathrm{C}$. Analyses were carried out at 1 and 21 days of storage at $4{ }^{\circ} \mathrm{C}$. The samples were analyzed in quadruplicate at each sampling time, and the analysis was repeated if necessary. Three yoghurt trials were carried out on three successive weeks. Analyses were carried out using two samples from each type of yoghurt at each trial.

\subsection{Chemical Analysis}

Acidity was measured by titration with $0.1 \mathrm{~N} \mathrm{NaOH}$, and expressed as a percentage of lactic acid [9]. The $\mathrm{pH}$ was determined with a $\mathrm{pH}$ meter (Thermo, Beverly, MA, USA).

Organic acids and sugars were analyzed according to the procedure described by Fernandez-Garcia and McGregor [10].

\subsection{Viscosity}

Apparent viscosity was measured with a Selecta rotational viscometer using Spindle No 4 at $10 \mathrm{rpm}$ (J. P. Selecta, Barcelona, Spain). Viscosity measurements were carried out at $4{ }^{\circ} \mathrm{C}$, with the sample in a $250 \mathrm{~mL}$ beaker. Yoghurt was gently stirred for $20 \mathrm{~s}$ before analysis and triplicate measurements were conducted.

\subsection{Sensory Analysis}

Sensory evaluation was performed by 5 experienced panelists (two males and three female) who have been trained with yoghurt sensory scores characteristics. The panel consisted of academic staff and students from Food Engineering Department of Mustafa Kemal University, Hatay, Turkey. Yoghurts were removed from refrigerator $\left(4^{\circ} \mathrm{C}\right) 1 \mathrm{~h}$ prior to sensory evaluation, kept at room temperature ( $22 \pm$ $\left.2^{\circ} \mathrm{C}\right)$. By using a 9 -point hedonic sale $(1=$ dislike extremely, $5=$ neither like nor dislike, $9=$ like extremely), consumers rated overall acceptability. Yoghurts were evaluated in duplicate by the panel members.

\subsection{Statistical analysis}

Statistical analysis of data obtained from yoghurts analysis for effects of two factors were performed using SPSS (Version 17.00) statistic program [11]. The factors were storage times (1 and 21 days), types of yoghurt. Effects of storage and type of yoghurt were seperately examined by one-way ANOVA, and the interaction between these factors was two-way analysis of variance (ANOVA). The mean differences were analyzed using Duncan's multiplerange test. The least significant difference $(\mathrm{P}<0.05)$ of the data is reported.

\section{Results and Discussion}

\subsection{Chemical Composition for Raw Milk and Variation in Acidity}

Cows' milk used for yoghurt manufacturing had $6.67 \mathrm{pH}$, $0.162 \%$ titratable acidity, $12.04 \%$ total solid, $3.40 \%$ crude fat, $4.55 \%$ lactose and $3.60 \%$ crude protein. As noted by Tamime and Robinson [12], milk had the minimum milk solids-non-fat content [8.2 to $8.6 \%$ ] requiring for yoghurtmaking.

The incubation of yoghurt samples was ended at $\mathrm{pH} 4.65$. The incubation time for control sample, milk fortified with wheat bran $(1 \%)(\mathrm{w} / \mathrm{w})$, carrot $(1 \%)(\mathrm{w} / \mathrm{w})$ and wheat bran $(1 \%)(\mathrm{w} / \mathrm{w})+\operatorname{carrot}(1 \%)(\mathrm{w} / \mathrm{w})$ was $319 \pm 11,311 \pm 9$, $337 \pm 12$ and $333 \pm 5 \mathrm{~min}$, respectively. Milk with wheat bran (1\%) showed the shortest incubation time. Wheat bran could be led to a stimulatory effect on the growth of Lactobacillus delbrueckii supsp. bulgaricus which is mainly reponsible for development of acidity [12]. At the beginning of storage, there were significant $(\mathrm{P}<0.05)$ differences in titratable acidity and $\mathrm{pH}$ values of yoghurt samples. As shown in Fig. 1., yoghurts made with wheat bran had the highest titratable acidity and the lowest $\mathrm{pH}$ with values of $0.99 \%$ (as lactic acid) and 4.35 , respectively. This result can explain why have the shortest incubation time of yoghurt made with wheat bran. As expected, the 
values of titratable acidity of the yoghurts significantly $(\mathrm{P}<0.05)$ increased at the end of storage. However, there were no significant changes in $\mathrm{pH}$ values of yoghurts except for control sample which showed a significant $(\mathrm{P}<0.05)$ decrease in $\mathrm{pH}$ at the end of storage (Fig. 1). Fortification could be resulted in a buffering capacity in yoghurts since the significant increases in acidity of yoghurts fortified with wheat bran and carrot were not accompanied by strong decreases in $\mathrm{pH}$.

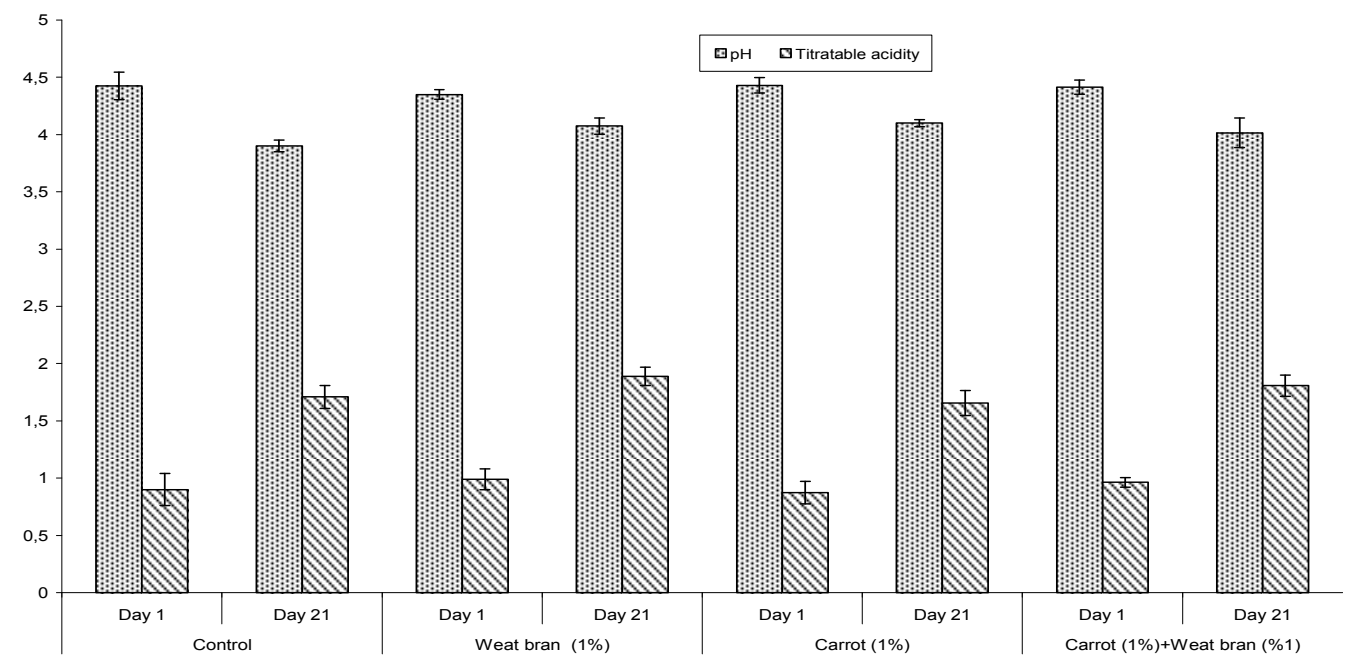

Fig. 1. Changes in the titratable acidity (as lLactic acid) and $p H$ values of control sample and yoghurts fortified with wheat bran (1\%) (w/w), carrot (1\%) $(w / w)$ and wheat bran $(1 \%)(w / w)+\operatorname{carrot}(1 \%)(w / w)$. The error bars are indicated standard deviation $(n=3, P<0.05 ; P<0.001)$.

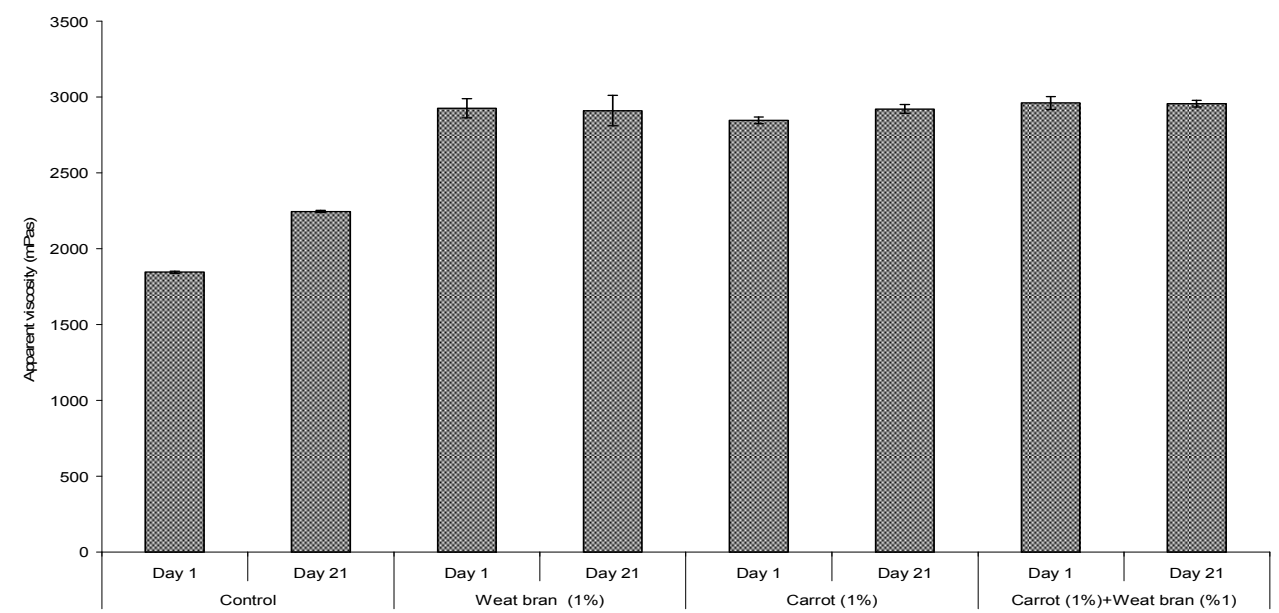

Fig. 2. Changes in viscosity of control sample and yoghurts fortified with wheat bran (1\%) (w/w), carrot (1\%) (w/w) and wheat bran (1\%) (w/w) + $\operatorname{carrot}(1 \%)(w / w)$. The error bars are indicated standard deviation $(n=3, P<0.05 ; P<0.001)$

\subsection{Evaluation of Organic Acids}

The organic acids in raw milk and yoghurt samples are given in Table 1. During manufacturing and storage of yoghurts there was an appreciable change in the individual organic acid. As noted by Adhikari et al. [13], propionic, butanoic and hippuric acids were not identified in milk, but they found in all the yoghurt samples. Oxalic acid was found in neither milk nor control yoghurt. Citric acid, a product of body metabolism, was predominant organic acid in milk with a value of $1773 \mathrm{mg} \mathrm{kg}^{-1}$. Citric acid accounted for about $86 \%$ of total organic acids in milk. The levels of organic acids identified in milk were similar to the values reported by Walstra and Jenness [14] . Concerning yoghurts, lactic acid was the principle organic acid in all the samples and its amount ranged from $90841 \mathrm{mg} \mathrm{kg}^{-1}$ to $10823 \mathrm{mg} \mathrm{kg}^{-1}$. The similar results were reported by Torre et al.[15]. At day 1, yoghurt made with wheat bran when compared with the other yoghurts contained lactic acid at the highest level $\left(9826 \mathrm{mg} \mathrm{kg}^{-1}\right)$. This result was in consistent with the high titratable acidity, low $\mathrm{pH}$ value and the low lactose content of yoghurt made with wheat bran. As mentioned previously, wheat bran could have supplied nutrients and growth stimulatory factors for yoghurt culture. There was a significant $(\mathrm{P}<0.05)$ increase in lactic acid contents of other samples except yoghurt made with carrot at the end of storage. 
Table 1. Organic acid and carbohydrate contents in milk, and carrot and wheat bran fortified yoghurts ( $n=3)$.

\begin{tabular}{|c|c|c|c|c|c|c|c|c|c|}
\hline \multirow[b]{3}{*}{ Acids $\left(\mathrm{mg} \mathrm{kg}^{-1}\right)^{1}$} & \multirow[b]{3}{*}{ Milk } & \multirow{2}{*}{\multicolumn{2}{|c|}{ Control $^{\mathrm{a}}$}} & \multirow{2}{*}{\multicolumn{2}{|c|}{$\begin{array}{l}\text { Wheat bran }(1 \%)^{b} \\
\text { Storage Days }\end{array}$}} & \multirow{2}{*}{\multicolumn{2}{|c|}{$\operatorname{Carrot}(1 \%)^{\mathrm{c}}$}} & \multirow{2}{*}{\multicolumn{2}{|c|}{$\begin{array}{l}\text { Carrot }(1 \%)+\text { Wheat } \\
\text { bran }(1 \%)^{d}\end{array}$}} \\
\hline & & & & & & & & & \\
\hline & & Day 1 & Days 21 & Day 1 & Days 21 & Day 1 & Days 21 & Day 1 & Days 21 \\
\hline Oxalic & nd & nd & nd & $9^{\mathrm{b}}$ & $10^{\mathrm{b}}$ & $2 \mathrm{a}$ & $2^{\mathrm{a}}$ & $8^{\mathrm{b}}$ & $10^{\mathrm{b}}$ \\
\hline Orotic & 118 & $116^{\mathrm{a}}$ & $106^{\mathrm{a}}$ & $374 \mathrm{c}$ & $353 \mathrm{c}$ & $147^{\mathrm{b}}$ & $133^{\mathrm{ab}}$ & $311 \mathrm{c}$ & $331 \mathrm{c}$ \\
\hline Citric & 1773 & $1726^{\mathrm{ab}}$ & $1689^{\mathrm{a}}$ & $1620^{\mathrm{a}}$ & $1667^{\mathrm{a}}$ & $1427^{\mathrm{a}}$ & $1584^{\mathrm{a}}$ & $1461^{\mathrm{a}}$ & $1596^{\mathrm{a}}$ \\
\hline Pyruvic & 25 & $49^{\mathrm{a}}$ & $47^{\mathrm{a}}$ & $68^{\mathrm{b}}$ & $66^{\mathrm{b}}$ & $48^{\mathrm{a}}$ & $44^{\mathrm{a}}$ & $63^{\mathrm{b}}$ & $55^{\mathrm{ab}}$ \\
\hline Uric & 20 & 22 & 22 & 25 & 26 & 23 & 22 & 23 & 23 \\
\hline Lactic & 715 & $9084^{\mathrm{a}}$ & $10823^{\mathrm{b}}$ & $9826^{\mathrm{b}}$ & $10562^{\mathrm{c}}$ & $9289^{\mathrm{a}}$ & $9673^{\mathrm{a}}$ & $9374^{\mathrm{ab}}$ & 10611 \\
\hline Formic & 782 & $665^{\mathrm{a}}$ & $802^{\mathrm{ab}}$ & $874^{\mathrm{b}}$ & $853^{\mathrm{ab}}$ & $760^{\mathrm{a}}$ & $721^{\mathrm{a}}$ & $824^{\mathrm{ab}}$ & $928^{\mathrm{ab}}$ \\
\hline Acetic & 96 & $124^{\mathrm{a}}$ & $128^{\mathrm{a}}$ & $213^{b}$ & $200^{\mathrm{b}}$ & $138^{\mathrm{a}}$ & $161^{\mathrm{a}}$ & $210^{\mathrm{b}}$ & $190^{\mathrm{b}}$ \\
\hline Propionic & nd & $90^{\mathrm{a}}$ & $100^{\mathrm{a}}$ & $165^{\mathrm{b}}$ & $202^{\mathrm{b}}$ & $101^{\mathrm{a}}$ & $110^{\mathrm{a}}$ & $155^{\mathrm{b}}$ & $194^{\mathrm{b}}$ \\
\hline Butanoic & nd & $201^{\mathrm{a}}$ & $218^{\mathrm{a}}$ & $230^{\mathrm{b}}$ & $239^{\mathrm{b}}$ & $237^{\mathrm{a}}$ & $189^{\mathrm{a}}$ & $221^{\mathrm{a}}$ & $243^{\mathrm{b}}$ \\
\hline Hippuric & nd & 17 & 15 & 30 & 29 & 19 & 20 & 24 & 20 \\
\hline Total organic acid & 3529 & 12094 & 13950 & 13434 & 14207 & 12191 & 12759 & 12674 & 14201 \\
\hline \multicolumn{10}{|l|}{ Sugars $\left(\mathrm{mg} \mathrm{kg}^{-1}\right)^{1}$} \\
\hline Lactose & 42358 & $30121 \mathrm{c}$ & $28553^{b}$ & $26239^{a}$ & $25446^{\mathrm{a}}$ & 29614 c & $28412^{b}$ & $25947^{\mathrm{a}}$ & $25494^{\mathrm{a}}$ \\
\hline Glucose & 169 & $2231^{\mathrm{a}}$ & $3152^{\mathrm{b}} \mathrm{c}$ & $2823 \pm^{\mathrm{b}}$ & $3585 \mathrm{c}$ & $2320^{\mathrm{a}}$ & $2378^{a}$ & $2788^{\mathrm{b}}$ & $3642 c$ \\
\hline Galactose & 42 & $6906^{\mathrm{a}}$ & $7509^{a b}$ & $7160 \pm^{a}$ & $7641^{\mathrm{ab}}$ & $6847^{\mathrm{a}}$ & $7121^{a}$ & $6611^{\mathrm{a}}$ & $7468^{\mathrm{ab}}$ \\
\hline Total sugar & 42569 & 39258 & 39214 & 36222 & 36672 & 38781 & 37911 & 35346 & 36604 \\
\hline
\end{tabular}

${ }^{a}$ Control yoghurt; ${ }^{b}$, Wheat bran (1\%) (w/w) fortified yoghurt; ${ }^{c}$, carrot (1\%) (w/w) fortified yoghurt; ${ }^{d}$, carrot (1\%) (w/w), and wheat bran (1\%) (w/w) fortified yoghurt. SD; standart devition.nd: not detected.

${ }^{I}$ Means for the the same parameters and treatment followed by different superscript letters are significantly different (P<0.05).

Citric acid was the second most abundant organic acid in yoghurt samples. The fermentation of milk led to a significant $[\mathrm{P}<0.01]$ decrease in citric acid contents of yoghurts fortified with wheat bran and carrot in comparison with control sample in which the negligible utilization of citric acid was observed during fermentation process and storage. This result is in acordance with the finding of FernándezGarcía and McGregor [8].The amount of citric acid was slightly increased in yoghurts made with wheat bran and carrot at the end of storage. This could be attributed to the hydrolsis of wheat bran and carrot by yoghurt culture depending on the development of acidity. Formic acid was the third most abundant acid in all the yoghurts. As shown in Table 1 , formic acid in milk was significantly $(\mathrm{P}<0.001)$ utilized by yoghurt culture during fermentation process for control sample and yoghurt made with carrot. However, it showed an increase tendency in yoghurts with wheat bran in comparison with raw milk. It could be argued that yoghurt culture was probably used wheat bran as substrat for formic acid production. At the end of storage, no signifi- cant changes in formic acid were observed for experimental yoghurts, but it increased significantly $(\mathrm{P}<0.05)$ in control yoghurt. This result was in consistent with a significant reduce in $\mathrm{pH}$ of control yoghurt at the end of storage. Formic acid contents of yoghurts were similar to findings of Bevilacqua and Califano [16]. Orotic, uric and hippuric acids are nonprotein nitrogenous compounds in milk, all of which were found in the yoghurts, whereas hippuric was not detected in milk. Orotic and hippuric acids were significantly $(\mathrm{P}<0.001)$ higher in yoghurts made with wheat bran than the other samples. This result was confirmed to the high level of titratable acidity of yoghurt with wheat bran since orotic acid was described as a growth factor for $L$. delbrueckii subsp. bulgaricus and also as a precursor for the synthesis of nucleotides [10]. Similarly, the concentrations of oxalic, propionic and butanoic acids were significantly $(\mathrm{P}<0.01)$ greater in yoghurts fortified with wheat bran and wheat bran+carrot than control and samples with carrot. This situation may be related to wheat bran used which is probably contained the high levels of oxalic, orot- 
ic and hippuric acids even though they were not detected since oxalic acid may produce from gylcolate by glycolate oxidase in plants [17]. Among organic acids derived from mainly glucose, pyruvic acid showed the lowest level, ranged from $44 \mathrm{mg} \mathrm{kg}^{-1}$ to $68 \mathrm{mg} \mathrm{kg}^{-1}$ yoghurt. Pyruvic acid acts as substitute in various metabolic pathways for the mainly acetic and formic acids [18].

Acetic acid was significantly $(\mathrm{P}<0.001)$ increased in all the yoghurts in comparison with raw milk, but it did not change at the end of refrigerated storage. The concentration of acetic acid was significantly $(\mathrm{P}<0.01)$ higher in yoghurts fortified with wheat bran and wheat bran +carrot than control and carrot fortified yoghurts. In a previous study, the synthesis of acetic, butanoic and propionic acids was increased in the mediums containing wheat bran [19].

Overall, yoghurt with carrot had the lowest post acidification rate and titratable acidity was contained total organic acid at the lowest level (12759 mg kg-1) at the end of storage. This could be attributed to the inhibitory effect of fruit sugars on acidification rate of yoghurt culture [12].

Of organic acids identified in yoghurts, in spite of the adverse effects of orotic and uric acids on gut flora, lactic, butanoic and acetic acids have a bacteriocidal or bacteriostatic effect. They suppress the multification of pathogenic and putrefying bacteria [20]. On the other hand, the most common kind of kidney stone is made of calcium oxalate which can irritate the gut and kidneys. Due to high oxalic acid content, long-term consumption of yoghurt fortified with wheat bran may lead to nutrient deficiencies

Concerning carbohydrates, the about $38 \%$ of lactose in milk was utilized by yoghurt bacteria in samples with wheat bran and wheat bran + carrot in comparison with the other yoghurt samples (about 30\%). The sugars such glucose and galactose were significantly $(\mathrm{P}<0.05)$ increased in the yoghurt samples except yoghurt with carrot at the end of storage. The most decrease in lactose was observed for control yoghurt at the end of storage. This can explain that the break down of supplement is mainly responsible for the increase in acidity of yoghurts fortified with wheat bran since the highest level of total organic acids was observed for yoghurts with wheat bran.

\subsection{Viscosity}

As shown in Fig. 3., fortification of milk with wheat bran and carrot resulted in a significant $(\mathrm{P}<0.05)$ increase in apparent viscosity of yoghurts at the beginning of storage. This could be attributed to interactions between the hydrocolloids in wheat bran and carrot, and milk proteins. Typically an increase in viscosity would suggest a decrease in syneresis probably because of more water being held within yoghurts with carrot and wheat bran. At the end of storage, a significant $(\mathrm{P}<0.05)$ increase in apparent viscosity was observed for control yoghurt only. This could be attributed to the protein rearrangements in acid casein gels at refrigerated storage depending on the decrease in $\mathrm{pH}$ since a significant decrease in $\mathrm{pH}$ value and the most increase in titratable was observed for control yoghurt only at the end of storage.

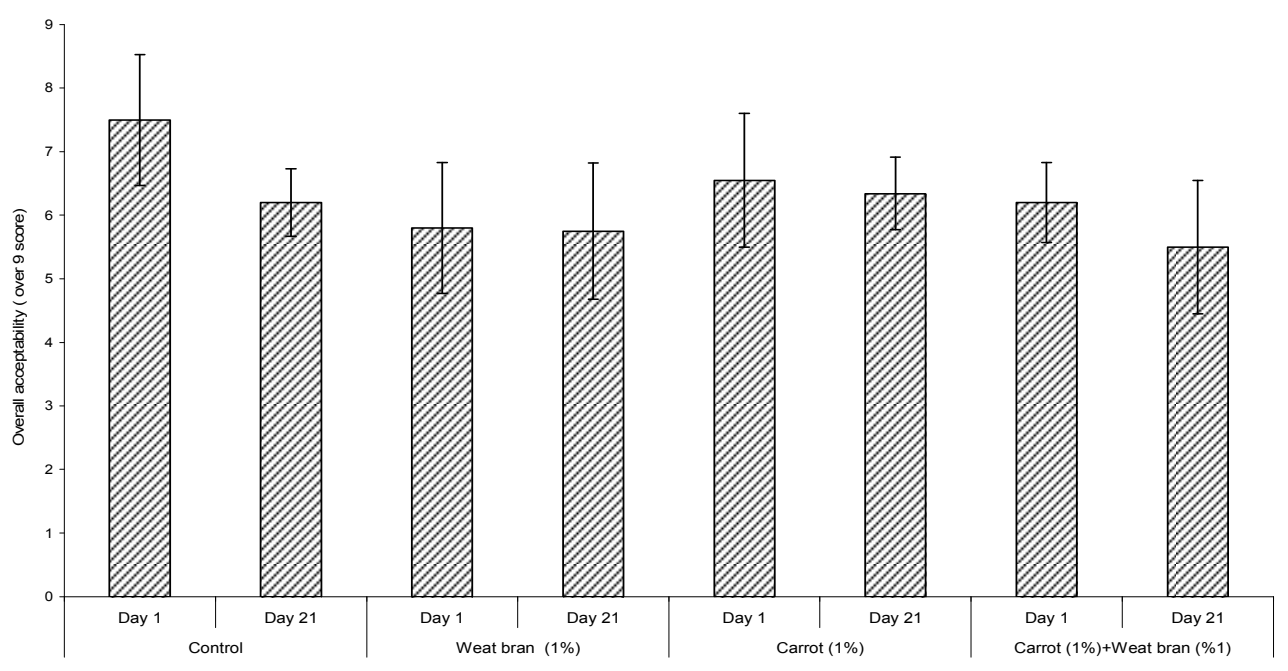

Fig. 3: Overall acceptability scores of control sample and yoghurts fortified with wheat bran (1\%) (w/w), carrot (1\%) (w/w) and wheat bran (1\%) $(w / w)+\operatorname{carrot}(1 \%)(w / w)$. The error bars are indicated standard deviation $(n=3, P<0.05 ; P<0.001)$

\subsection{Overall acceptability}

At the begining of storage, overall acceptability score ( 7.50 out of 9.0) was significantly $(\mathrm{P}<0.05)$ high in control yoghurt followed by yoghurts made with carrot, wheat bran+carrot and wheat bran. At the end of storage, the decrease in overall acceptability score of control yoghurt was significant $(\mathrm{P}<0.05)$, whereas the other yoghurts did not any change. It is accepted that formic acid as well as lactic acid have a very important effect on the overall acceptability of yoghurt since these acids increased significantly $(\mathrm{P}<0.01)$ in control sample at the end of storage. In addition, overall acceptability is closely related to the amount of total organic acid and titratable acidity level 
since yoghurts with high total organic acid (14200 $\left.\mathrm{mgkg}^{-1}\right)$ and titratable acidity $(1.85 \%$, as lactic acid) received the lowest overall acceptability score.

\section{Conclusion}

The lactic acid accounted for about $90 \%$ of the total organic acid content of yoghurts, followed in decreasing order by citric, formic, butanoic acid, orotic, acetic, propionic, hippuric, uric and oxalic acids. Fortification with wheat bran resulted in an increase in total organic acid, acidification rate and apparent viscosity, and a decrease in total sugar content as well as overall acceptability score of yoghurt. At the end of storage the least increases in total organic acid and titratable acidity were observed for yoghurt fortified with carrot. Therefore, yoghurt fortified with carrot may be suitable for long-time storage. Control yoghurt which had the lowest levels of lactic $\left(9100 \mathrm{mg} \mathrm{kg}^{-1}\right)$ and formic $\left(665 \mathrm{mg} \mathrm{kg}^{-1}\right)$ acids was much more prefered by panelists. In general, yoghurts had total organic acid content at above about $10000 \mathrm{mg} \mathrm{kg}^{-1}$ showed a significant $(\mathrm{P}<0.01)$ decrease in overall acceptability score. It is worth noting that the use of carrot as a supplement when compared to wheat bran may be more suitable for yoghurt production since it led to a slow acidification rate, the less organic acid production and the higher overall acceptability in yoghurt at the end of storage.

\section{Acknowledgements}

The author is thankful to Gülay Çevikgil, Gülcan Güren, Esra Özen and Ali Orkun Cicekcioglu for their assistance in conducting the experiments at the Food Engineering Department, Mustafa Kemal University, Hatay, Turkey.

\section{References}

[1] Hekmat, S., \& McMahon, D. Manufacture and quality of iron fortified yoghurt, Journal of Dairy Science 80 (1997), 3114-3122.

[2] Adolfsson, O., Nikbin-Meydani, S., and Russell, R. M. Yoghurt and gut fuction, American Journal of Clinical Nutrition 80 (2004), pp. 245-256.

[3] Brady, L. J., \& Gallaher, D. D. The role of probiotic cultures in the prevention of colon cancer, Journal Nutrition 130 (2000), pp. 410-414.

[4] Wollowski, I., Rechkemmer, G., and Pool-Zobel, B. L. Protective role of probiotics and prebiotics in colon cancer, American Journal Clinical Nutrition 73 (2001), pp. 451S$455 S$.

[5] Shah, N., Atallah, M. T., Mahoney, R. R., and Pellett, P. T. Effects of dietary fiber components of fecal nitrogen extrac- tion and protein utilization in growing rats, Journal Nutrition 112 (1982), pp.658-666.

[6] Özcan, M. M., \& Chalchat, J. C. Chemical composition of carrot seeds (Daucus carota L) cultivated in Turkey: characterization of the seed oil and essential oil, Grasas Y Aceites, 58 (2007), pp. 359-365.

[7] Angelino, P. D. (1993) Integration of fiber ingredients in fluid dairy products. MSc Thesis, Louisiana State University, Baton Rouge.

[8] Fernandez-García, E., \& McGregor, J.U. Fortification of sweetened plain yoghurt with insoluble dieatary fiber, $Z \mathrm{Le}$ bensm Unters Forsch A 204 (1997), pp. 433-437.

[9] TSI (2006). Yoghurt TS 1330 Ankara, Turkey: Turkish Standard Institution

[10] Fernandez-García, E., \& McGregor, J. U. Determination of Organic Acids During the Fermentationand Cold Storage of Yoghurt, Journal of Dairy Science 77 (1994), pp. 29342939.

[11] Stern, L.D. (2009). A visual approach to SPPSS for windows: A Guide to SPSS 17.0. $2^{\text {nd }}$ edition. Chicago: Pearson.

[12] Tamime, A. Y., \& Robinson, R. K. (2001). Yoghurt science and technology. New York: CRC Press.

[13] Adhikari, K., Grün, I. U., Mustapha, A., and Fernando, L. N. Changes in the profile of organic acids in plain set and stirred yoghurts during manufacture and refrigerated storage, Journal Food Quality 25 (2002), pp. 435-451.

[14] Walstra, P., \& Jenness, R. (1984). Dairy chemistry and physics. Toronto: John Willey \& Sons Inc.

[15] Torre, L. A., Tamime, A. Y., and Muir, D. D. Rheology and sensonry profiling of set-type fermented milks made with different commercial probiotic and yoghurt starter cultures, International Journal Dairy Technolog 56 (2003), pp. 163170 .

[16] Bevilacqua, A. E., \& Califano, A. N. Determination of organic acids in dairy products by high performance liquid chromatography, Journal Food Science 54 (1989), pp.1076-1079.

[17] Davies, D.D., Asker, H. Synthesis of oxalic acid by enzymes from lettuce leaves. Plant Physiology 72 (1983), pp. $134-138$.

[18] McSweeney, P.L.H.; Sousa, M.J. Biochemical pathways for the production of flavour compounds in cheese during ripening: a review. Lait 80 (2000), pp.293-324.

[19] Madhukumar, M. S., Muralikrishna, G. Structural charactersation and determination of prebiotic activity of purified xylo-oligosaccharides obtained from Bengal gram husk (Cicer arietinum L.) and wheat bran (Triticum aestivum), Food Chemistry 118 (2010), pp.215-223.

[20] Miller, G. D., Jarvis, J. K., and McBean, L.D. (2000) Handbook of dairy foods and nutrition, $2^{\text {nd }}$ ed. New York: CRC Press. 